\title{
Water Resources Analysis: An Approach based on Agent-Based Modeling
}

\section{Análise de Recursos Hídricos: Uma Abordagem Baseada na Modelagem de Agentes}

\author{
Giovani P. Farias ${ }^{1 *}$, Bruna S. Leitzke ${ }^{1}$, Míriam B. Born², \\ Marilton S. de Aguiar ${ }^{2}$, Diana F. Adamatti ${ }^{1}$
}

\begin{abstract}
The paper aims to present a river basin modeling using GAMA platform for water resources analysis. Currently, several models based on multi-agent systems are used for natural resources management and they present satisfactory results for this type of scenario. GAMA is agents based and widely used in this context with several studies already published. In this study, the São Gonçalo and Lagoa Mirim basins were considered from georeferenced data. In the modeling, regions, and rivers are agents on the system where rivers water can flow among neighbors regions.

Keywords: Multi-Agent Systems - Natural Resources - Agent-Based Model — GAMA

Resumo: Este artigo tem por objetivo apresentar a modelagem de uma bacia hidrográfica para a análise do uso dos recursos hídricos utilizando a plataforma GAMA. Na atualidade, diversos modelos baseados em sistemas multiagente são utilizados para a gestão de recursos naturais e apresentam resultado satisfatório neste tipo de cenário. A ferramenta GAMA é baseada em agentes e amplamente utilizada neste contexto, com diversos estudos já publicados. Neste estudo, considerou-se a bacia hidrográfica São Gonçalo e Lagoa Mirim a partir de dados georreferenciados. Na modelagem, regiões e rios são agentes no sistema, sendo que a água dos rios pode fluir entre regiões vizinhas.

Palavras-Chave: Sistemas Multiagente - Recursos Naturais - Modelo Baseado em Agente - GAMA

${ }_{1}^{1}$ Programa de Pós-Graduação em Modelagem Computacional (PPGMC) - Universidade Federal do Rio Grande (FURG) - Brasil

${ }^{2}$ Programa de Pós-Graduação em Computação (PPGC) - Universidade Federal de Pelotas (UFPel) - Brasil

*Corresponding author: giovanifarias@gmail.com

DOI: http://dx.doi.org/10.22456/2175-2745.94319 • Received: 07/07/2019 • Accepted: 26/09/2019

CC BY-NC-ND 4.0 - This work is licensed under a Creative Commons Attribution-NonCommercial-NoDerivatives 4.0 International License.
\end{abstract}

\section{Introdução}

Recursos naturais compreendem os elementos da natureza aos quais seres humanos utilizam para sua sobrevivência, sendo estes renováveis ou não renováveis. Com a crescente demanda da população mundial, estes recursos tornam-se escassos em algumas regiões, além disso, o mau uso, a falta de gerenciamento e, às vezes, o compartilhamento dos mesmos acarretam em graves conflitos [1,2].

Modelos baseados em agentes são ferramentas que surgiram da necessidade de capturar melhor as características de sistemas complexos, em particular, os sistemas ecológicos e sociais, pois abrangem várias áreas de estudo. Deste modo, a partir da simulação multiagente, é possível projetar políticas adequadas para resolver os problemas mencionados [3].

Modelagem multiagente simula sistemas com base na tomada de decisões e ações de atores individuais ou grupos de atores, nas interações entre si e com o ambiente em que estão inseridos. A gestão de recursos renováveis em sistemas com- plexos, principalmente o recurso hídrico no contexto da bacia hidrográfica, é um importante meio na busca de possíveis soluções aos problemas enfrentados pelos interessados em um determinado ecossistema [4].

$\mathrm{O}$ gerenciamento de recursos naturais aliado a técnicas de Sistemas Multiagente (SMA) e jogos de papéis (RPG Role-Playing Game) são encontradas em diversos trabalhos e apresentam soluções interessantes. O RPG é bastante utilizado em estudos de caso que buscam uma solução compartilhada entre as partes interessadas de um sistema, sendo que esta abordagem auxilia na tomada de decisão [4]. Além destas técnicas, diversas ferramentas e plataformas são usadas em aplicações de SMA, entre as quais pode-se citar CORMAS e GAMA (GIS Agent-based Modeling Architecture) [5] amplamente difundas em pesquisas realizadas pelo grupo CIRAD, da França [6, 7].

Neste trabalho, propõe-se como estudo de caso a bacia hidrográfica Mirim-São Gonçalo, localizada no sudeste do Rio Grande do Sul, a qual possui abrangência nas províncias 
da planície costeira Uruguaio-Sul Riograndense. Alguns dos municípios que a bacia engloba são: Arroio Grande, Candiota, Canguçu, Capão do Leão, Chuí, Jaguarão, Pelotas, Rio Grande e Santa Vitória do Palmar, com uma área total de $25.961,04 \mathrm{~km}^{2}[8]$.

A modelagem da bacia foi realizada na plataforma de código aberto GAMA, sendo considerado os dados geográficos da região de estudo, onde cada região hidrográfica e seus rios foram considerados agentes no modelo. A simulação possibilita diversas análises do ambiente, tais como: consumo de água e taxa de produção por região, volume de água dos rios em cada região e fluxo de água entre rios de regiões vizinhas.

$\mathrm{O}$ artigo encontra-se organizado da seguinte forma. $\mathrm{Na}$ Seção 2 são apresentados conceitos básicos sobre Sistemas Multiagente. A Seção 3 apresenta os trabalhos relacionados que envolvem tecnologias similares as propostas neste trabalho. Na Seção 4 é introduzida a plataforma GAMA com suas características e funcionalidades. Na Seção 5 é apresentado o estudo de caso, bem como, a modelagem da bacia hidrográfica com a utilização da plataforma GAMA. As análises das simulações, realizadas no modelo de bacia hidrográfica, estão na Seção 6. Finalmente, a Seção 7 apresenta as conclusões e trabalhos futuros.

\section{Sistemas Multiagente}

$\mathrm{O}$ uso de Sistemas Multiagente atualmente abrange pesquisas direcionadas a diversos temas sobre o gerenciamento de ecossistemas. Com essa técnica é possível reproduzir o conhecimento e raciocínio de vários agentes heterogêneos que, juntos, precisam resolver problemas comuns de planejamento [9]. Segundo [10], os agentes de um sistema devem cooperar, aprender e agir de forma autônoma. Desta maneira, os classifica em:

i. agentes reativos, os quais reagem a eventos no ambiente em que estão inseridos de acordo com regras/normas especificadas previamente;

ii. agentes de interface que têm o intuito de auxiliar o usuário nas diversas aplicações;

iii. agentes de informação que auxiliam o usuário a encontrar, classificar e filtrar informações provenientes de inúmeras fontes da internet;

iv. agentes colaborativos, os quais cooperam entre si para alcançar objetivos/metas.

Sistemas Multiagente constituem-se de diversos agentes interagindo em um ambiente, sendo introduzidos na Computação na década de 80 , porém, somente nos anos 90 tornaram-se populares [11]. Cada agente do sistema possui comportamento individual e deve ser capaz de interagir com os demais de forma organizada, desta maneira são relevantes as características de [12]: cooperação, coordenação, competição e negociação. Tais características tornam-se importantes pois a maioria dos problemas a serem resolvidos buscam uma maneira distribuída de resolução. Além disso, muitos destes possuem elevada complexidade, tornando impossível encontrar a solução apenas com um agente. Em SMA, agentes podem cooperar em busca da solução de um objetivo geral, sendo que, cada um destes possui seu próprio objetivo, mas juntos, podem alcançar uma meta maior $[13,12]$. Os benefícios de utilizar SMA são diversos, tais como:

i. rapidez na resolução de problemas visto a inerência do processamento concorrente;

ii. aumento da flexibilidade e escalabilidade através da conexão de vários sistemas;

iii. aumento da capacidade de resposta a um determinado problema pelo fato de todos os recursos estarem localizados no mesmo ambiente.

No desenvolvimento de SMA, uma arquitetura comumente utilizada é a BDI (Beliefs, Desires and Intentions), baseada num modelo cognitivo que representa crenças, desejos e intenções [14]. De acordo com [11] a arquitetura BDI é estruturada da seguinte forma:

i. crenças representam o que o agente sabe sobre si mesmo, sobre os demais agentes e sobre o ambiente ao qual está inserido;

ii. desejos representam os estados que o agente almeja atingir, geralmente são tratados como objetivos;

iii. intenções são representadas pela sequência de ações que um determinado agente executa para alcançar um objetivo.

Para simular sistemas complexos é necessário compreender a dinâmica e o funcionamento característico deste tipo de sistema. Eles podem ser representados por uma grande variedade de interação entre os agentes envolvidos. Algumas ferramentas são específicas para a simulação de SMA, sendo que, no estudo deste artigo, voltado para a bacia hidrográfica Mirim-São Gonçalo, foi escolhida a plataforma GAMA [5].

Outras ferramentas vêm sendo utilizadas para a simulação em aplicações de SMA, os autores [15] utilizaram a estrutura JaCaMo [16] (Jason [17], CArtAgO [18] e $\mathscr{M}$ OISE [19]), que cobre alguns dos níveis de abstrações necessários para o desenvolvimento de SMA, para analisar um experimento de ecossistema urbano. Utilizando o modelo de simulação do consumo urbano no Netlogo, [20] analisaram os sistemas de alocação e fluxo de água, energia e alimento. Com o intuito de desenvolver um RPG (Role-Playing Game) chamado ReHab, [21] propuseram uma modelagem baseada em multiagente para harmonização entre regeneração de biomassa e habitat de reprodução de aves migratórias protegidas, onde a implementação foi realizada na plataforma CORMAS [6]. 


\section{Trabalhos Relacionados}

$\mathrm{Na}$ literatura, diversos trabalhos utilizam SMA no contexto do gerenciamento de recursos naturais, bem como a integração de Simulação Baseada em Multiagentes (MABS - Multi-AgentBased Simulation) e Jogos de Papéis (RPG - Role-Playing Games) aplicados juntamente à outras ferramentas.

No trabalho [22], os autores utilizaram a metodologia denominada GMABS criada a partir da integração do RPG e SMA. Com base nesta metodologia foram desenvolvidos dois protótipos: o JogoMan que consiste em um jogo de papéis com um número mínimo de jogadores os quais devem estar fisicamente presentes em local e horário específico.

No segundo protótipo chamado ViP-JogoMan, foi possível inserir jogadores virtuais que conseguissem reproduzir comportamentos reais e capturar autonomia, habilidades sociais, reação e adaptação de jogadores reais. Os jogadores virtuais foram modelados utilizando a arquitetura BDI e como conclusão do trabalho os autores apresentam alguns resultados de testes obtidos com os dois protótipos, bem como uma discussão preliminar sobre como a inserção de jogadores virtuais afetou os resultados do jogo.

Em [23] é relatado as experiências e lições aprendidas a partir da aplicação de um modelo baseado em agente para estudar as dinâmicas e interações complexas entre as partes interessadas no manejo florestal, gerenciadas por três vilarejos na Ilha Palawan (Filipinas). Neste modelo foi utilizada a abordagem Commod (The Companion Modeling), que consiste na aplicação de RPG e simulação computacional, a fim de desenvolver um plano colaborativo de gerenciamento de recursos. A conclusão obtida nesta pesquisa foi que o uso de RPG e a simulação multiagente permitiram aos pesquisadores entender como os atores envolvidos agem em relação à tomada de decisão sobre um ambiente controlado e também como elaboram estratégias de gerenciamento de recursos.

No trabalho de [24], os autores apresentam um modelo multiagente criado a partir da abordagem Commod do Vale do Rio Kat, Cabo Oriental, África do Sul. Este SMA foi denominado KatAWARE e, neste trabalho, o objetivo foi propor uma metodologia detalhada para formalizar e sistematizar as fases de modelagem desta abordagem. No contexto, o estudo de caso foi a bacia hidrográfica de Kat River e a especificação da estrutura do sistema e sua dinâmica foi representada em diagramas baseados em UML (Unified Modeling Language). Dessa forma, o trabalho apresentou o processo de desenvolvimento da ferramenta KatAWARE, em três versões consecutivas e melhoradas com o objetivo de agregar as inúmeras fontes de conhecimento e dados, desenvolvendo um plano de manejo coletivo. As informações obtidas em cada sessão de RPG deram suporte aos cenários das simulações. E assim, o RPG provou ser uma ferramenta facilitadora nessas discussões, onde a implementação e as simulações foram importantes para explorar cenários e discutir resultados.

$\mathrm{O}$ artigo [25] apresenta aspectos teóricos e experimentais da abordagem Commod, utilizando como experimento o conflito entre duas comunidades étnicas e um parque nacional no norte da Tailândia. Nas sessões de RPG, foram discutidas questões fundamentais sobre desmatamento, conservação da biodiversidade e meios de subsistência da comunidade, e a partir disso, a informação foi representada em um simulador multiagente. A conclusão desta pesquisa mostrou que as interações colaborativas entre pesquisadores e partes interessadas aumentaram a comunicação e a aprendizagem coletiva, melhorando a gestão integrada do desenvolvimento sustentável de recursos renováveis.

Em [26], os autores propõem a criação de um RPG, baseado na abordagem Commod, para facilitar a negociação sobre o gerenciamento de escoamento erosivo. O Thegame foi organizado em duas sessões com dois diferentes comitês de gestão de bacias hidrográficas em Pays de Caux (França), com o objetivo de discutir e compartilhar conhecimentos sobre o meio ambiente e as partes interessadas. As informações obtidas durante as sessões de RPG forneceram suporte às simulações. Nos resultados relatados pelos autores, apesar da complexidade inerente do problema de gestão, o grupo de jogadores conseguiu reduzir o fluxo de erosão em $20 \%$ a $50 \%$ através de um diálogo sobre pastagens, estocagem e gestão do período de entressafra.

O trabalho de [27] apresenta as mudanças no uso da terra na ilha de Ushan, que faz parte do Parque Natural Regional de Armorique na Bretanha - França. Essa região sofreu deslizamentos de terra, resultando em consequências na paisagem, atividades tradicionais e biodiversidade. A partir da abordagem Commod, os pesquisadores, juntamente com o gerente da reserva da biosfera e o Centro de Estudos do Milieud, realizaram um estudo sobre as interações entre as dinâmicas sociais e ambientais nesta ilha protegida. Os objetivos do trabalho foram: a concepção de um modelo, a implementação de um SMA geográfico e o desenho de um jogo de RPG, para auxiliar na tomada de decisão das partes interessadas, no manejo sustentável do uso da terra, e na sinergia com as políticas de gestão local.

O SMA foi desenvolvido com base no método ARDI e projetado e implementado na plataforma CORMAS no qual foi refinado e validado em quatro etapas da discussão. Sessões de RPG foram realizadas com indivíduos envolvidos no projeto. Ao final de cada rodada do jogo, o SMA fornecia mapas, dados estatísticos e simulações em 2D e 3D que viabilizava as mudanças de terra induzidas pelas ações dos jogadores. Discussões foram realizadas após as sessões onde as partes envolvidas tiveram um olhar crítico e compararam os resultados do jogo à realidade.

No trabalho [28], é desenvolvida a modelagem de um SMA para investigar as interações entre a disponibilidade de água, terra e a migração de mão-de-obra na produção de arroz, a partir do conhecimento prévio de um grupo de produtores do nordeste da Tailândia. Em primeiro lugar, famílias agrícolas jogaram um RPG para descobrir a dinâmica do ambiente e melhorar as novas sessões de jogo, e depois, para desenvolver o SMA. Como resultado, os autores concluíram que esse modelo é uma ferramenta de comunicação que pode ser usada 
por cientistas locais e agricultores e foi desenvolvida para trocar e gerar conhecimento sobre as interações do uso de água e terra, e migração laboral.

Na pesquisa apresentada em [29], os autores analisam a disseminação de informações sobre o Manejo Integrado de Pragas (MIP) em comunidades de pequenos agricultores andinos, no Peru. Os pesquisadores desenharam um SMA do sistema agrícola andino e então, desenvolveram o RPG como modelo de papéis. O jogo foi testado com 90 agricultores de batata sendo estes de seis comunidades em três países. Após as sessões de RPG, os pesquisadores realizaram entrevistas com os agricultores e concluíram que o RPG baseado em SMA é uma ferramenta que pode ser usada para o ensino e a disseminação de informações do MIP, o que permite reduzir a vulnerabilidade aos riscos de pragas na região.

O trabalho [21] apresenta o jogo ReHab. É um jogo baseado em RPG usado para introduzir as principais ideias de gestão natural para os alunos nos primeiros anos de um curso de pós-graduação na área. O objetivo principal do jogo é encontrar o equilíbrio do ambiente e é dividido em duas fases: a primeira, onde os jogadores não podem comunicar-se com os colegas e devem escolher suas ações individualmente; a segunda, onde os estudantes comunicam-se com os colegas e tomam suas decisões sobre as ações do jogo. Todo o sistema é computacional e cada jogador joga em um computador. Os autores concluíram que um RPG bem projetado permite que os jogadores modelem, aprendam e reflitam sobre as respostas do sistema socioecológico de forma individual ou coletiva, considerando vários regimes de gerenciamento.

A ideia do trabalho em [30] é propor uma nova abordagem para modelar uma simulação multiagente participativa, chamada KILT. Esta abordagem difere das abordagens KISS e KIDS, bem conhecidas na literatura, porque as simulações podem ser estilizadas para os ecossistemas sociais e estimulam a aprendizagem social das partes interessadas, onde estas jogam em cartões e as ações são computadas em uma simulação multiagente. Os autores concluem que, com essa abordagem, o foco da interação pode ser definido nas interações do participante do computador (os participantes observam a simulação na forma de um público de cinema) ou nas interações participante-participante (os participantes podem intervir enquanto a simulação é executada ou em intervalos fornecidos durante a corrida).

É importante ressaltar que, neste trabalho, optou-se por utilizar a plataforma de modelagem, desenvolvimento e simulação baseada em agentes GAMA, visto que, a mesma permite uma integração de forma mais rápida e clara com sistemas de informações geográficas, o que contribuiu para uma importação de forma mais fácil dos dados referentes a bacia hidrográfica Mirim-São Gonçalo.

\section{Plataforma GAMA}

A plataforma GAMA ${ }^{1}$ (GIS Agent-based Modeling Architecture) é um ambiente de desenvolvimento integrado completo, que permite alternar de forma rápida e prática entre perspectivas de modelagem e simulação. GAMA é baseada na consolidada IDE (Integrated Development Environment) do Eclipse, utilizando os diversos recursos presentes neste ambiente de desenvolvimento, e é desenvolvida por várias equipes da unidade internacional de pesquisa UMMISCO (Unité de Modélisation Mathématique et Informatique des Systèmes Complexes) no IRD (Institut de Recherche pour le Développement) da UPMC (Université Pierre et Marie Curie) como um projeto open source desde o ano de 2007.

A plataforma apresenta um editor que visa facilitar o trabalho de modelagem e desenvolvimento do usuário (Figura 1), contendo ferramentas usuais de IDEs, tais como: coloração da sintaxe, compilação e preenchimento automáticos e a possibilidade de formatar ou comentar linhas de código específicas. Além disso, a IDE está conectada a uma extensa documentação online, permitindo aos usuários a obtenção de informações sobre as diversas palavras-chave, operadores e declarações disponíveis.

$\mathrm{O}$ ambiente de desenvolvimento integrado permite formular e construir modelos baseados em agentes, a partir de diferentes conjuntos de dados, possuindo integração com sistemas de informações geográficas (GIS - Geographic Information System). Além disso, a flexibilidade de sua interface permite organizar os painéis de visualização com comandos simples de arrastar e soltar ou através de layouts predefinidos, apresentando uma ferramenta de inspeção/verificação de agentes, a qual permite obter informações sobre um ou vários agentes (visão tabular), e também possui um mecanismo de busca desenvolvido para a obtenção de informações e exemplos de uso dos diversos operadores presentes na plataforma.

A plataforma de desenvolvimento, modelagem e simulação GAMA [5] tem por objetivo fornecer ferramentas para desenvolver e testar modelos complexos por meio da integração entre programação baseada em agentes, gerenciamento de dados geográficos, ferramentas de visualização flexíveis e representação em vários níveis [31, 32]. GAMA fornece uma linguagem de modelagem completa GAML (GAma Modeling Language) e um ambiente de desenvolvimento integrado que permite formular e construir modelos de forma tão rápida e fácil quanto no NetLogo [33], indo além do que Repast (Recursive Porous Agent Simulation Toolkit) [34] ou que Mason (Multi-Agent Simulator Of Neighborhoods) [35].

Atualmente, GAMA é utilizada em vários modelos, como $[36,37]$ e também em projetos, como sistemas de apoio a decisões ambientais [38], projetos urbanos [39], gerenciamento de recursos hídricos [40], invasões biológicas [41] e adaptação às mudanças climáticas ou mitigação de desastres [7].

\footnotetext{
${ }^{1}$ https://gama-platform.github.io/
} 


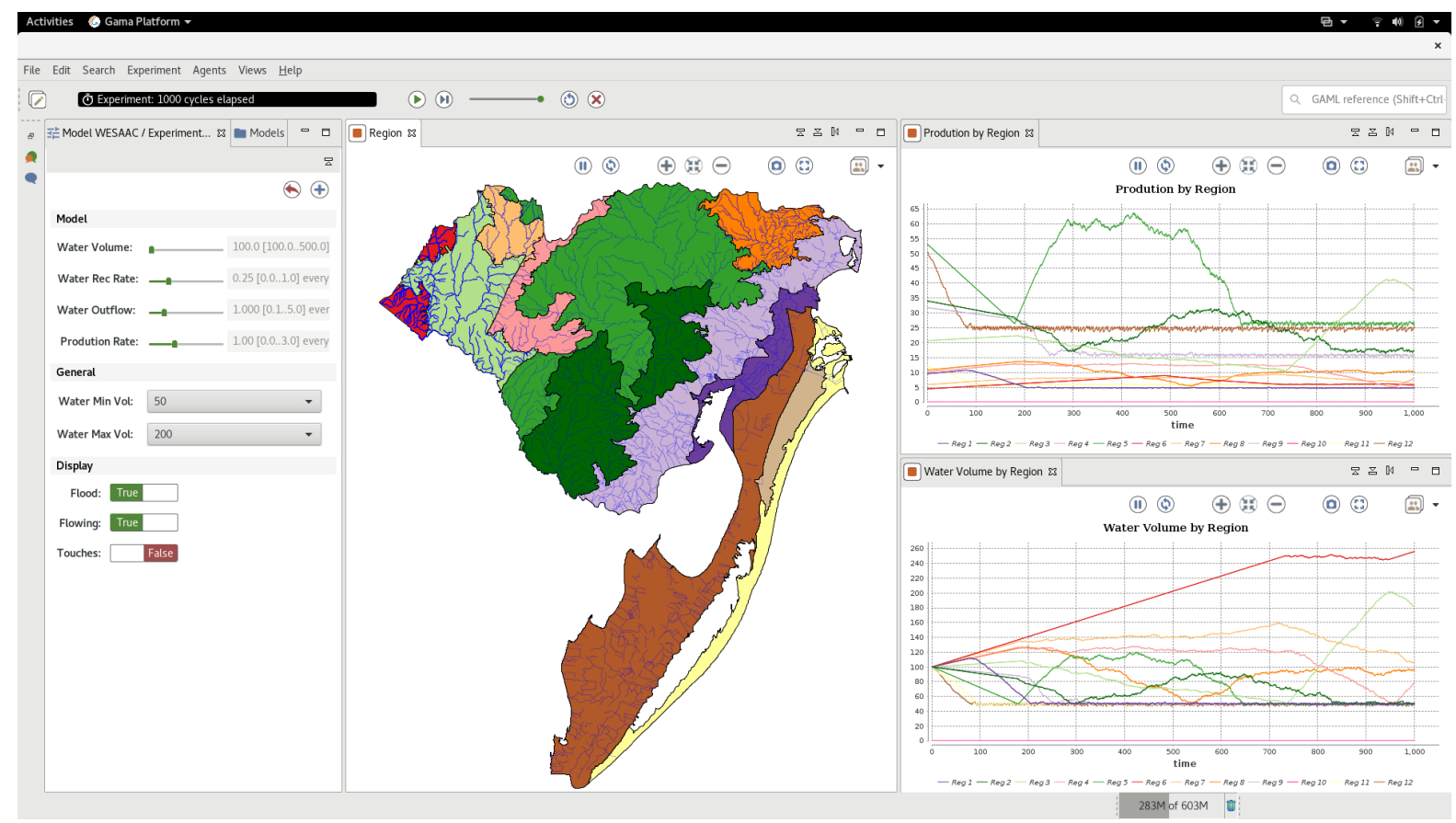

Figura 1. Interface da bacia Mirim-São Gonçalo na plataforma GAMA

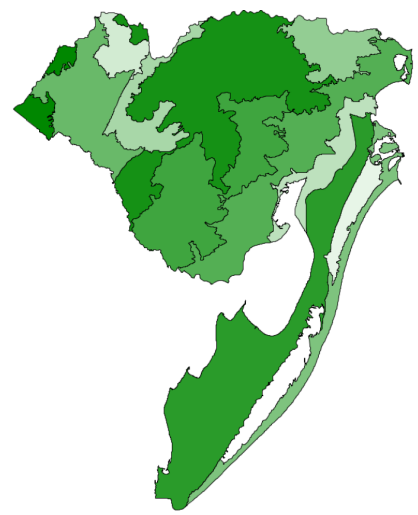

(a) regiões

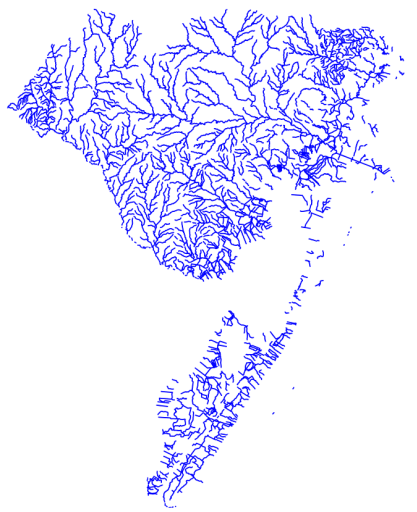

(b) rios

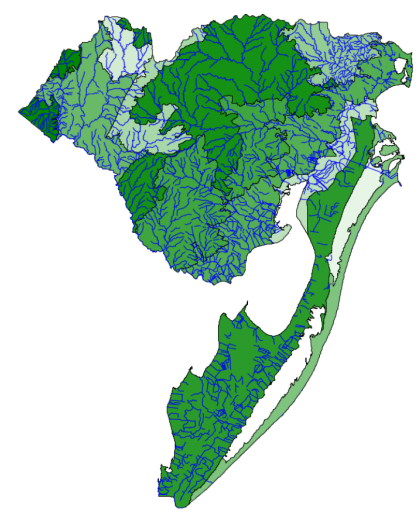

(c) regiões e rios

Figura 2. Representação gráfica da bacia hidrográfica Mirim-São Gonçalo

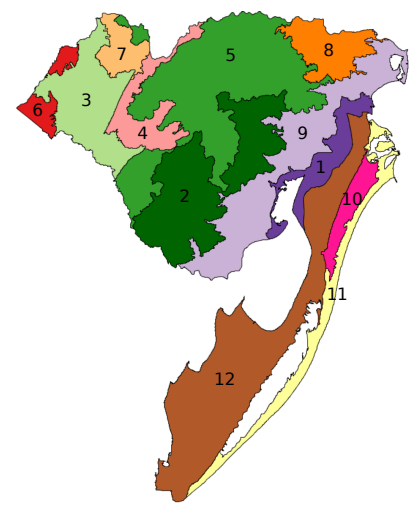

(a) regiões numeradas

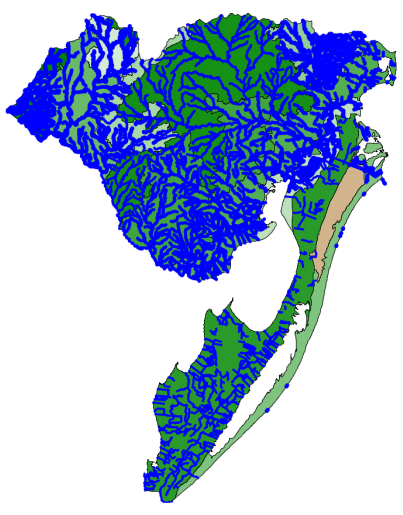

(b) rios alagados

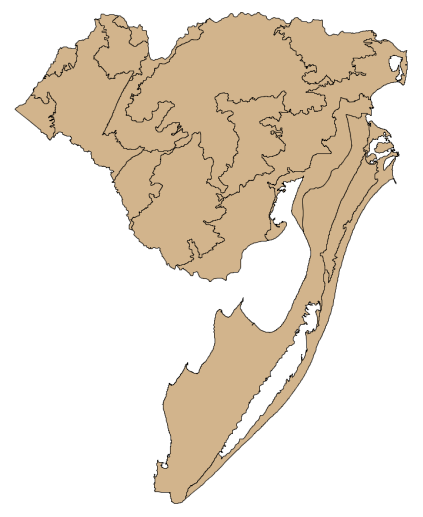

(c) rios secos

Figura 3. Representação das regiões, cenário de alagamento e seca extrema 


\section{Modelagem do Problema}

Uma bacia hidrográfica pode ser considerada como uma parte territorial importante para a hidrologia urbana, pois ela relaciona a geografia natural da região, a água, a civilização e a população. Dessa forma, existe a necessidade de gerir as bacias hidrográficas a partir de questões sociais, econômicas e ambientais. Neste trabalho, apresenta-se a modelagem de uma bacia hidrográfica com a utilização da ferramenta GAMA, que permite lidar facilmente com dados geoespaciais e vetoriais de sistemas de informação geográfica.

O modelo de dados GIS utilizado neste trabalho, representa uma base de dados com informações geográficas, que encontra-se em três arquivos no formato shapefile, contendo informações geoespaciais da bacia hidrográfica Mirim-São Gonçalo. Esses arquivos, descrevem espacialmente qualidades de vetores (pontos, linhas e polígonos) para representar as regiões, capacidades de uso do solo e os rios presentes na bacia, sendo que, cada um desses itens possui ainda atributos que o descrevem, como: nome, código, área, comprimento, etc. A plataforma GAMA consegue separar esses itens em diferentes camadas temáticas e representá-los de forma independente, permitindo trabalhar com eles de modo rápido e simples. Deste modo, cada região, tipo de capacidade de uso do solo ou rio pode ser considerado um agente específico com suas próprias características e atributos.

Na Figura 2a, por exemplo, pode-se visualizar o formato e localização de cada região, bem como acrescentar o atributo cor a cada uma delas com tonalidade própria. GAMA permite ao usuário relacionar as informações existentes através da posição e topologia dos objetos, gerando assim novas informações. Neste caso, considerando a junção das informações na Figura 2a (regiões) e na Figura $2 b$ (rios), obtêm-se a representação presente na Figura 2c (regiões e rios), da qual, a plataforma consegue extrair novas informações e atributos para cada objeto, como associar um rio a uma determinada região de acordo com sua localização.

Tabela 1. Atributos básicos da região conforme sua área.

\begin{tabular}{c|r|c|r|r|l}
\hline região & area $\mathrm{km}^{2}$ & cons & prd & $\mathrm{n}$ o rios & vizinhos \\
\hline 1 & 956.55 & 0.09 & 9.5 & 161 & {$[9,12]$} \\
2 & 3402.83 & 0.34 & 34 & 358 & {$[5,9]$} \\
3 & 2069.33 & 0.20 & 20.6 & 255 & {$[4,5,6,7]$} \\
4 & 1016.72 & 0.10 & 10.1 & 24 & {$[3,5,7]$} \\
5 & 5306.11 & 0.53 & 53 & 216 & {$[2,3,4,7,8,9]$} \\
6 & 448.17 & 0.04 & 4.4 & 66 & {$[3]$} \\
7 & 590.02 & 0.05 & 5.9 & 22 & {$[3,4,5]$} \\
8 & 1081.65 & 0.10 & 10.8 & 213 & {$[5,9]$} \\
9 & 3178.26 & 0.31 & 31.7 & 503 & {$[1,2,5,8]$} \\
10 & 564.70 & 0.05 & 0 & 0 & {$[11,12]$} \\
11 & 1199.01 & 0.11 & 11.9 & 24 & {$[10,12]$} \\
12 & 5047.57 & 0.50 & 50.4 & 452 & {$[1,10,11]$} \\
\hline
\end{tabular}

O modelo hidrográfico presente neste trabalho é composto por 12 regiões (Figura 3a), com características distintas conforme o tamanho de sua área (Tabela 1) ou de acordo com os tipos de capacidade de uso do solo presentes na região

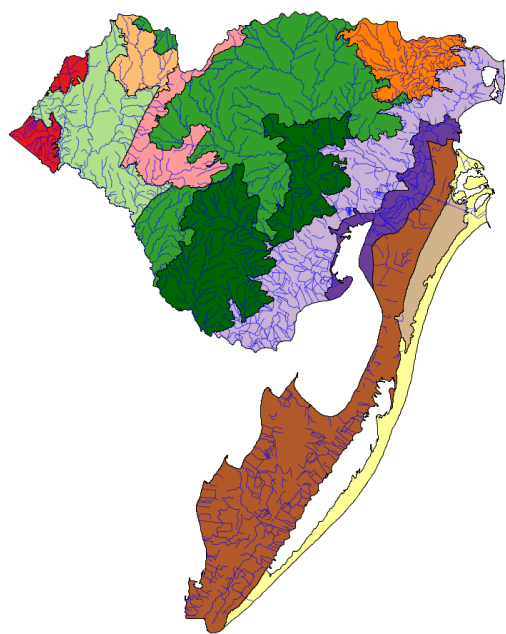

(a)

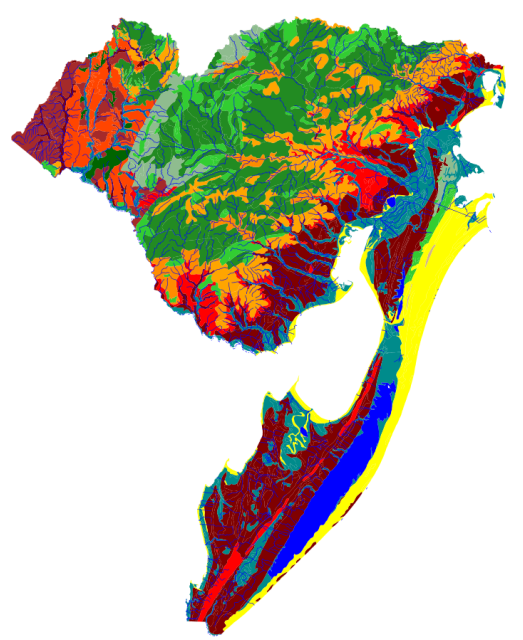

(b)

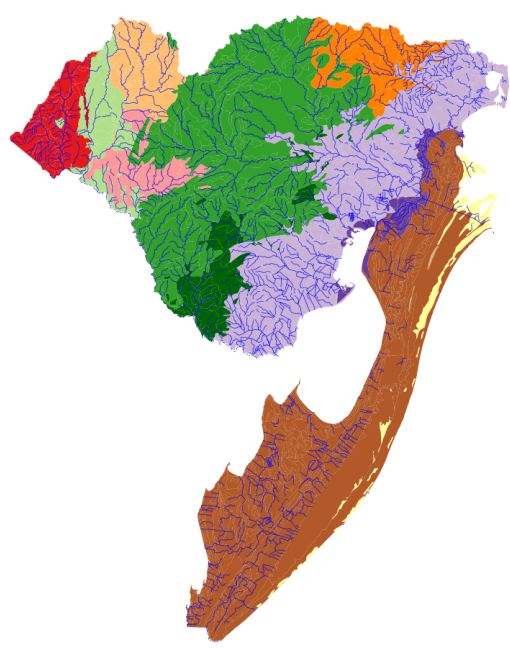

(c)

Figura 4. Divisão da bacia hidrográfica: (a) regiões; (b) tipos de capacidade de uso do solo; (c) capacidades de uso do solo associadas a cada região 
(Tabela 2). De acordo com a Tabela 1, cada região apresenta valores específicos para taxa de produção de bens/serviços ( prd) e consumo de água (cons), os quais, estão relacionados com o tamanho da sua área (area). Neste caso, regiões com uma área maior apresentam uma taxa de produção e consumo de água maiores.

O modelo hidrográfico também fornece a subdivisão da bacia de acordo com o tipo de capacidade de uso do solo, conforme apresentado na Figura 4b. Deste modo, cada região possui um conjunto com os diversos tipos de uso do solo que estão associados a sua posição geoespacial (Figura 4c).

A Tabela 2 apresenta os valores da taxa de produção ( $p r d)$ e consumo de água (cons) de acordo com os tipos de capacidade de uso do solo associados a cada região (Figura 4c). Cada tipo de capacidade de uso influencia na produção ( $p r d$ ) e consumo (cons) de acordo com o valor de seu índice "i" e quantidade "qtd" presente na região $T_{i}(q t d)$, ou seja, quanto maior o valor do seu índice e quantidade na região, maior será a produção e consumo da região. Deste modo, o tipo que menos produz e consome água é $T_{0}$, consequentemente, o tipo que mais produz e consome água é $T_{12}$. A bacia é composta por 1.144 divisões do solo de acordo com a sua capacidade de uso, sendo que, cada uma dessas divisões pertence a um dos 13 tipos de uso do solo a seguir:

$T_{0}$ : (Figura $4 \mathrm{~b} / \mathrm{cor}$ azul) são áreas cobertas por água.

$T_{1}$ : (Figura 4b / cor verde-azulado) áreas inundáveis desde períodos muito pequenos a permanentes, submersas por riachos, rios e lagoas. Aproveitáveis com pastoreiro nos períodos secos ou de baixo alagamento, algumas são próprias a projetos de drenagem localizados. Os solos hidromórficos são muito diversificados, sendo terras próprias a cultivos perenes e pastagens temporárias.

$T_{2}$ : (Figura $4 \mathrm{~b} /$ cor amarelo) são terras arenosas costeiras que variam desde muito alagadas a dunas itinerantes e transitórias. Comportam pastagens nativas ou cultivadas, silvicultura ou áreas arenosas sem uso agrícola. Terras próprias a cultivos perenes e silvicultura.
$T_{3}$ : (Figura $4 \mathrm{~b} / \mathrm{cor}$ verde limão) são áreas rochosas que podem ser aproveitadas com silvicultura, pastagem nativa ou até mesmo atividades fora da agricultura devido aos solos rasos e rochosos, a ocorrência de rochas e alta suscetibilidade a erosão. Solos rasos e rochosos, podem ser aproveitadas com silvicultura e pastagem nativa.

$T_{4}$ : (Figura $4 \mathrm{~b} /$ cor verde mar escuro) terras próprias a cultivos perenes e silvicultura. Áreas próprias a roças familiares de pequenas dimensões. Predominam solos rasos muito suscetíveis à erosão.

$T_{5}$ : (Figura $4 \mathrm{~b} /$ cor verde floresta) são áreas altas de relevo ondulado a forte ondulado do complexo cristalino principalmente, com solos profundos, rasos, cascalhentos e fortes declives. O controle dos processos erosivos deve ser antecipado aos cultivos, sendo próprias a cultivos ocasionais. São áreas intermitentes favoráveis entre outras rochosas próprias a cultivos anuais.

$T_{6}$ : (Figura 4b / cor verde escuro) são áreas de colinas gondwânicas (sedimentos do Triássico) de relevo suave ondulado com encostas íngremes e processos erosivos naturais acentuados. Os solos são muito férteis, imperfeitamente drenados e muito suscetíveis à erosão devido à falta de agregação entre as suas unidades estruturais. Terras próprias a cultivos anuais.

$T_{7}$ : (Figura 4b / cor laranja) são as áreas de coxilhas com relevo ondulado, muito suscetíveis a erosão, em virtude dos declives acentuados. Possuem solos profundos de média fertilidade. Terras próprias a cultivos anuais e aptas para cultivos aráveis, com fortes limitações.

$T_{8}$ : (Figura 4b / cor laranja escuro) são áreas suave onduladas nas colinas interserranas que, por seus solos profundos, bem drenados e de média fertilidade, se inserem entre as terras altas onduladas ou rochosas. São próprias a agricultura tecnificada com riscos a erosão. Terras próprias a cultivos anuais e aptas para cultivos aráveis, mas com algumas limitações que restringem a escolha de plantas ou requerem moderadas práticas de conservação.

Tabela 2. Atributos básicos de cada região conforme seu conjunto de tipos de capacidade de uso do solo.

\begin{tabular}{c|r|r|r|l|r}
\hline região & \multicolumn{1}{c|}{ cons } & \multicolumn{1}{|c|}{ prd } & $\mathrm{n}^{\mathbf{o}}$ tipos & \multicolumn{1}{|c|}{ conjunto de tipos de uso do solo $-\left[T_{i}(q t d)\right]$} & total \\
\hline 1 & 0.06 & 12 & 3 & {$\left[T_{0}(1) ; T_{1}(44) ; T_{2}(8)\right]$} & 53 \\
2 & 0.54 & 108 & 7 & {$\left[T_{1}(7) ; T_{7}(5) ; T_{8}(6) ; T_{3}(9) ; T_{10}(20) ; T_{5}(11) ; T_{12}(14)\right]$} & 72 \\
3 & 0.865 & 173 & 8 & {$\left[T_{1}(34) ; T_{3}(5) ; T_{5}(6) ; T_{6}(7) ; T_{9}(25) ; T_{10}(2) ; T_{11}(17) ; T_{12}(26)\right]$} & 122 \\
4 & 0.106 & 21.2 & 8 & {$\left[T_{1}(2) ; T_{3}(4) ; T_{4}(7) ; T_{5}(2) ; T_{6}(1) ; T_{9}(3) ; T_{10}(1) ; T_{11}(1)\right]$} & 21 \\
5 & 0.881 & 176.2 & 9 & {$\left[T_{1}(1) ; T_{3}(64) ; T_{4}(12) ; T_{5}(52) ; T_{7}(25) ; T_{8}(14) ; T_{10}(7) ; T_{11}(1) ; T_{12}(1)\right]$} & 177 \\
6 & 0.221 & 44.2 & 7 & {$\left[T_{1}(1) ; T_{3}(1) ; T_{6}(2) ; T_{7}(1) ; T_{9}(2) ; T_{11}(12) ; T_{12}(4)\right]$} & 23 \\
7 & 0.374 & 74.8 & 8 & {$\left[T_{1}(2) ; T_{3}(11) ; T_{4}(1) ; T_{5}(12) ; T_{7}(17) ; T_{9}(7) ; T_{11}(3) ; T_{12}(5)\right]$} & 58 \\
8 & 0.136 & 27.2 & 5 & {$\left[T_{1}(1) ; T_{3}(18) ; T_{5}(10) ; T_{7}(3) ; T_{10}(1)\right]$} & 33 \\
9 & 1.579 & 315.8 & 6 & {$\left[T_{1}(79) ; T_{2}(23) ; T_{3}(1) ; T_{7}(15) ; T_{10}(47) ; T_{12}(73)\right]$} & 238 \\
10 & 0.004 & 0 & 1 & {$\left[T_{2}(2)\right]$} & 2 \\
11 & 0.157 & 31.4 & 4 & {$\left[T_{1}(14) ; T_{2}(16) ; T_{3}(1) ; T_{12}(9)\right]$} & 40 \\
12 & 1.649 & 329.8 & 7 & {$\left[T_{0}(5) ; T_{1}(128) ; T_{2}(38) ; T_{3}(15) ; T_{4}(2) ; T_{10}(6) ; T_{12}(111)\right]$} & 305 \\
\hline
\end{tabular}


$T_{9}$ : (Figura 4b / cor vermelho alaranjado) são as áreas suave onduladas com solos argilosos muito férteis, mas com deficiência de drenagem interna. Ocorrem nas colinas gondwânicas, na borda do planalto, sendo próprias a uma agricultura tecnificada com riscos a erosão. Terras próprias a cultivos anuais e aptas para cultivos aráveis, mas com algumas limitações que restringem a escolha de plantas ou requerem moderadas práticas de conservação.

$T_{10}$ : (Figura $4 \mathrm{~b} / \mathrm{cor}$ vermelho) áreas planas ou suave onduladas com solos férteis, profundos e imperfeitamente drenados como os que ocorrem nas lombadas. São terras próprias as atividades agrícolas praticamente sem riscos de erosão. Terras próprias a cultivos anuais e aptas para cultivos aráveis, mas com algumas limitações que restringem a escolha de plantas ou requerem moderadas práticas de conservação.

$T_{11}$ : (Figura $4 \mathrm{~b} /$ cor castanho) são áreas com relevo suave ondulado e ondulado nas colinas gondwânicas, com solos muito férteis, imperfeitamente drenados, internamente, e muito suscetíveis a erosão. São solos desenvolvidos de formações sedimentares argilosas do Triássico. Terras próprias a cultivos anuais e aptas para cultivos aráveis, com fortes limitações.

$T_{12}$ : (Figura $4 \mathrm{~b} /$ cor marrom) são áreas de planícies sedimentares quaternárias não inundáveis, com solos hidromórficos rasos e de má drenabilidade, em virtude de uma camada argilosa impermeável. Não oferecem riscos de erosão. São próprias a alguns cultivos anuais irrigados além do arroz. Terras próprias a cultivos anuais e aptas para cultivos aráveis, com fortes limitações.

O ambiente também é composto por 2.294 rios que estão distribuídos entre as diversas regiões de acordo com sua posição geoespacial. Todos os rios apresentam os mesmos valores para o volume de água ( $v o l)$ inicial, a taxa de recuperação de água (rec) e o fluxo de água ( $f$ tuxo).

$\mathrm{O}$ volume de água dos rios diminui com o passar do tempo de acordo com a taxa de consumo de água da região na qual o rio está inserido. Os rios recuperam parte do seu volume de água de acordo com a taxa de recuperação de água, que é um valor global do ambiente igual para todos os rios.

Cada rio pertence a uma única região e todos os rios de uma mesma região possuem o mesmo volume de água. Se o consumo de água da região é menor que a taxa de recuperação de água, a tendência é que o volume dos rios cresçam no decorrer do tempo e a região fique alagada (Figura 3b), caso contrário, quando o consumo de água da região é maior que a taxa de recuperação de água, a tendência é que o volume dos rios cheguem a zero, isto é, os rios secam (Figura 3c), tornando a região totalmente improdutiva até o final da simulação.

Regiões vizinhas podem compartilhar água de seus rios quando o valor do fluxo de água for maior que zero. É importante observar que uma região só pode obter água quando atingir um volume mínimo ( $m i n_{-} v o l$ ) estabelecido no ambiente, da mesma forma, uma região só pode "ceder" água a um vizinho quando seu volume de água for maior que este volume mínimo. $\mathrm{O}$ ambiente também estabelece um valor para o volume máximo de água ( $\left.\max _{-} v o l\right)$, neste caso, quanto mais o volume de água da região ultrapassar este valor (alagamento), menor será sua taxa de produção.

\section{Simulações e Análises}

A interface de simulação do modelo hidrográfico da bacia Mirim-São Gonçalo (Figura 1), desenvolvido na plataforma GAMA, possibilita a representação gráfica (mapa), da variação dos volumes dos rios e alteração das cores das regiões que secam, bem como, a visualização em gráfico de linhas da variação da taxa de produção e do volume de água em cada região. Além disso, permite atribuir diferentes valores aos diversos parâmetros de configuração do ambiente.

Neste trabalho, são apresentados resultados e análises de quatro simulações, duas considerando o valor da área da região para o cálculo da produtividade e consumo de água e duas considerando os tipos de capacidade de uso do solo presentes na região. Todas as simulações possuem os seguintes valores globais:

- volume de água inicial $v o l=100$;

- taxa de recuperação da água $r e c=0.15$;

- volume mínimo de água min_vol = 25;

- volume máximo de água max_vol = 200 .

A única diferença entre as simulações, além do cálculo ser baseado na área da região ou no tipo de uso do solo, é que nas simulações da Seção 6.1 o valor do fluxo de água é 1.5 (fluxo $>0$ ), ou seja, é permitido o compartilhamento de água entre regiões vizinhas. Ao contrário, nas simulações da Seção 6.2, o valor do fluxo de água é zero $(f l u x o=0)$, ou seja, não há compartilhamento de água entre regiões. Os demais valores específicos para cada região estão representados nas Tabelas 1 e 2, para cálculos baseados na área e no tipo de uso do solo, respectivamente.

\subsection{Simulações COM partilha de água entre regiões}

$\mathrm{Na}$ simulação com partilha de água entre regiões vizinhas e cálculo da produtividade e consumo de água baseado na área, podemos observar que regiões com áreas maiores, quando atingem o volume mínimo de água, passam a "consumir" água dos vizinhos (Figura 6a), pois observa-se que as regiões com áreas menores têm volume de água crescente no começo da simulação, o qual começa a diminuir na medida que regiões maiores atingem o volume mínimo de água $($ min_vol $=25)$. Neste caso, regiões com consumo de água maior que 0.15 (cons $>0.15$ ) tendem a secar de forma gradual no decorrer do tempo (visualmente, ficam na cor cinza), conforme apresentado na Figura 5. 


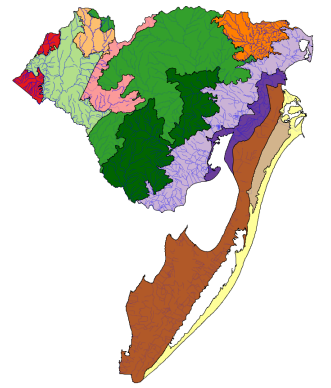

(a) 100

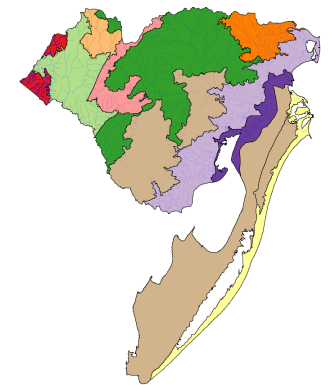

(b) 500

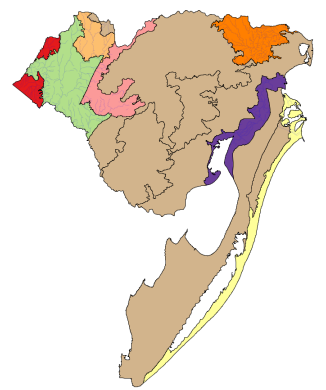

(c) 1000

Figura 5. Alterações no ambiente no decorrer do tempo baseadas no tamanho da área da região (COM partilha de água)

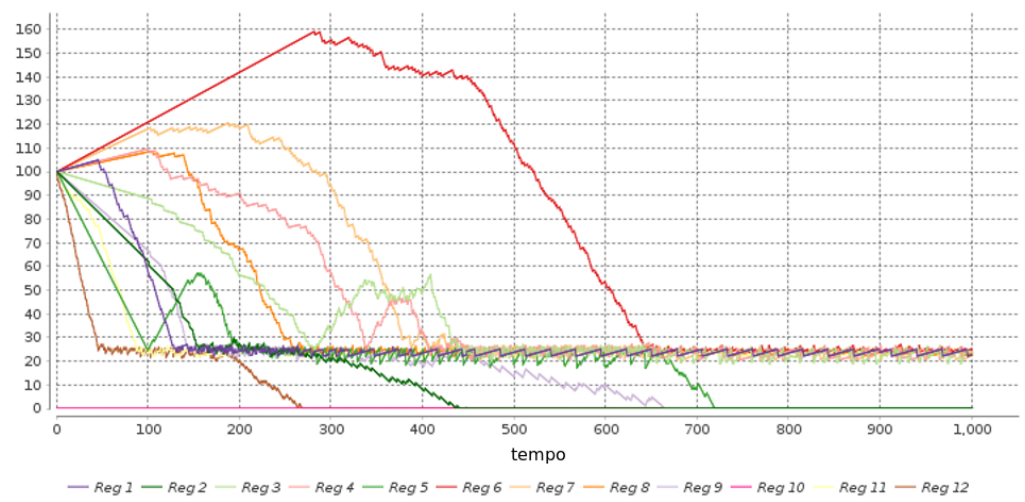

(a) volume de água por região

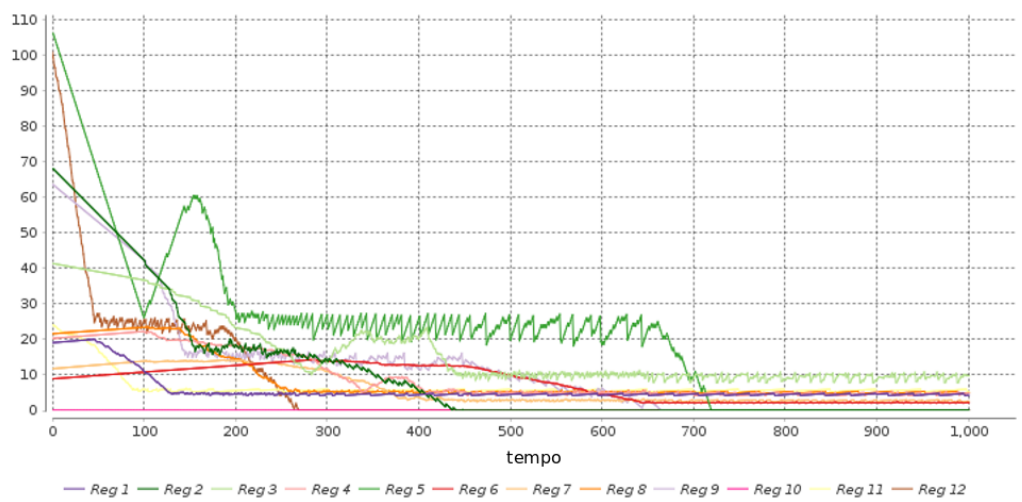

(b) produção por região

Figura 6. Variação do volume de água e produção baseada no tamanho da área da região (COM partilha de água)

Na simulação baseada no valor da área também podemos observar que:

i. a região 10 , mesmo possuindo cons $<0.15$, acaba secando, pois ela não possui nenhum rio;

ii. a região 3, apesar de possuir cons $>0.15$, não seca, pois está cercada de vizinhos aptos a partilhar água;

iii. após o passo 700, tanto o consumo de água (Figura 6a) quanto a produção (Figura 6b) se estabilizam.

Na simulação com partilha de água e cálculo baseado nos tipos de capacidade de uso do solo associados à região, pode- mos observar que as regiões 12 e 9 secam antes de atingirem o passo 50 (Figura 7a), pois são as regiões mais produtivas e, consequentemente, consomem um maior volume de água. Ambas são vizinhas da região 1 (região com o menor consumo de água) e mesmo compartilhando recursos dessa região não conseguem manterem-se produtivas. No passo 500, praticamente todas as regiões, com consumo de água maior que 1.5 já tornaram-se improdutivas (Figura 7b). A única exceção é a região 11 que permanece produtiva por um período maior devido ao seu consumo de água ser próximo da taxa de recuperação do ambiente (Tabela 2). Porém, no decorrer do tempo esta região também acaba secando (Figura 7c). 


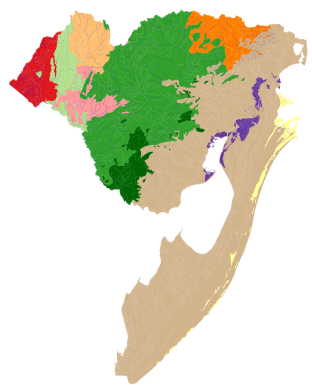

(a) 50

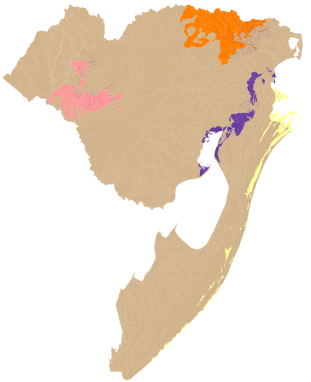

(b) 500

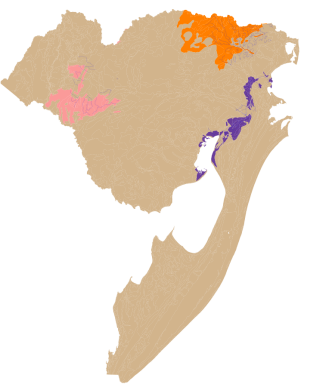

(c) 2000

Figura 7. Alterações no ambiente no decorrer do tempo baseadas no tipo de uso do solo da região (COM partilha de água)

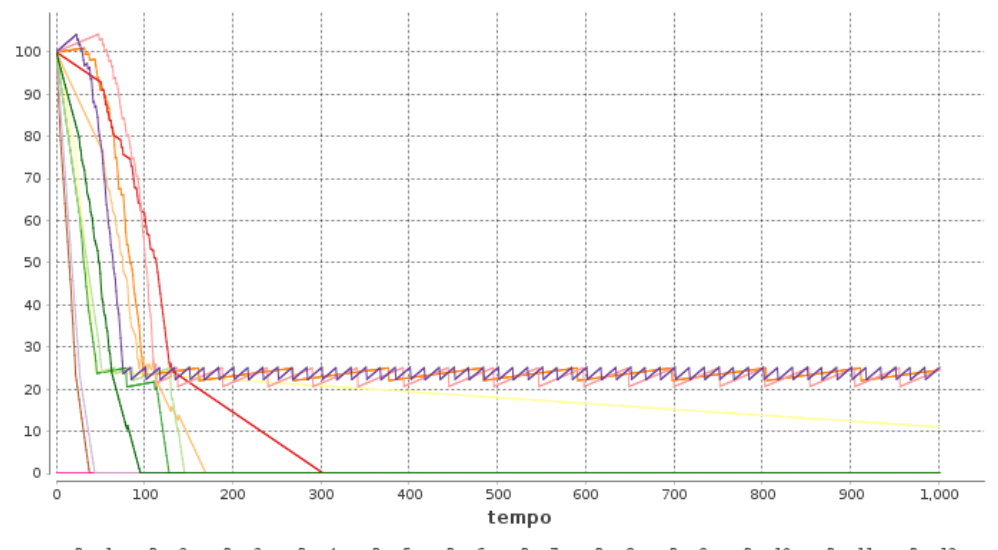

(a) volume de água por região

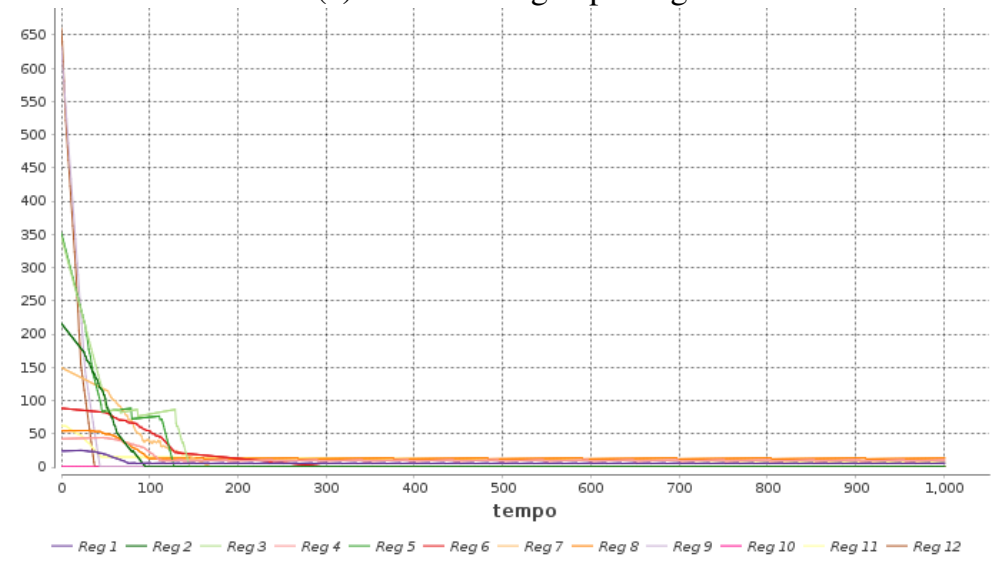

(b) produção por região

Figura 8. Variação do volume de água e produção baseada no tipo de uso do solo da região (COM partilha de água)

A queda dos valores do volume de água (Figura 8a) e produtividade (Figura 8b) das regiões são mais abruptas se comparadas a simulação que considera o valor da área. Além disso, nenhuma região com consumo maior que a taxa de recuperação conseguiu manter-se produtiva através do compartilhamento de água com regiões vizinhas, ao contrário do que ocorreu na simulação anterior, onde a região 3 consegue manter-se produtiva graças ao compartilhamento de água com seus vizinhos. Na simulação baseada no tipo de uso do solo podemos observar que:

i. a região 10 continua improdutiva pelo fato de não possuir nenhum rio;

ii. apesar do compartilhamento de água, todas as regiões com consumo maior que a taxa de recuperação de 1.5 tornaram-se improdutivas;

iii. no decorrer do tempo, apenas as regiões 1,4 e 8 conseguiram manter-se produtivas (Figura 7c). 


\subsection{Simulações SEM partilha de água entre regiões}

Nas simulações sem partilha de água entre regiões vizinhas, independente do cálculo ser pelo valor da área ou pelo tipo de uso do solo, podemos observar que regiões com consumo de água maior que a taxa de recuperação (cons $>0.15)$, quando atingem o volume mínimo de água, não “consomem” água dos vizinhos, permanecendo o comportamento de queda linear do volume de água (Figuras 10a e 12a) das regiões com consumo de água maior que 0.15 , as quais, tendem a secar de forma mais abrupta no decorrer do tempo, conforme apresentado nas Figuras 9 e 11.
Regiões com consumo de água menor que 0.15 (cons $<$ 0.15 ) apresentam um crescimento linear do volume de água durante toda simulação, porém este crescimento linear não se reflete em um crescimento contínuo da produção (Figuras 10b e 12b).

Podemos observar que a produção das regiões com maior consumo (cons) diminui conforme a queda no volume de água, até atingir o valor zero, caso este, onde os rios secaram e a região tornou-se totalmente improdutiva. As regiões com consumo de água menor que a taxa de recuperação do ambiente apresentam um crescimento linear do volume de água e de

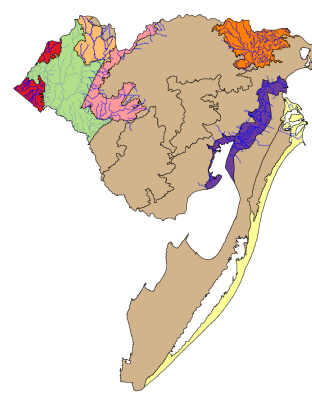

(a) 500

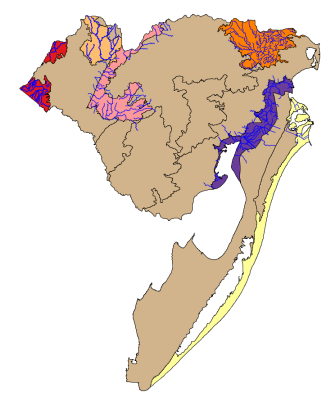

(b) 1000

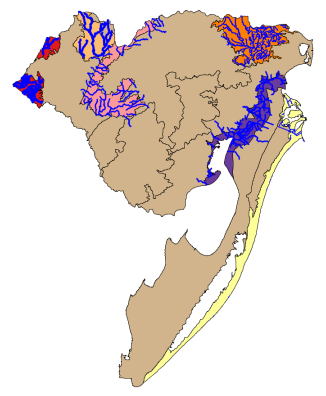

(c) 3500

Figura 9. Alterações no ambiente no decorrer do tempo baseadas no tamanho da área da região (SEM partilha de água)

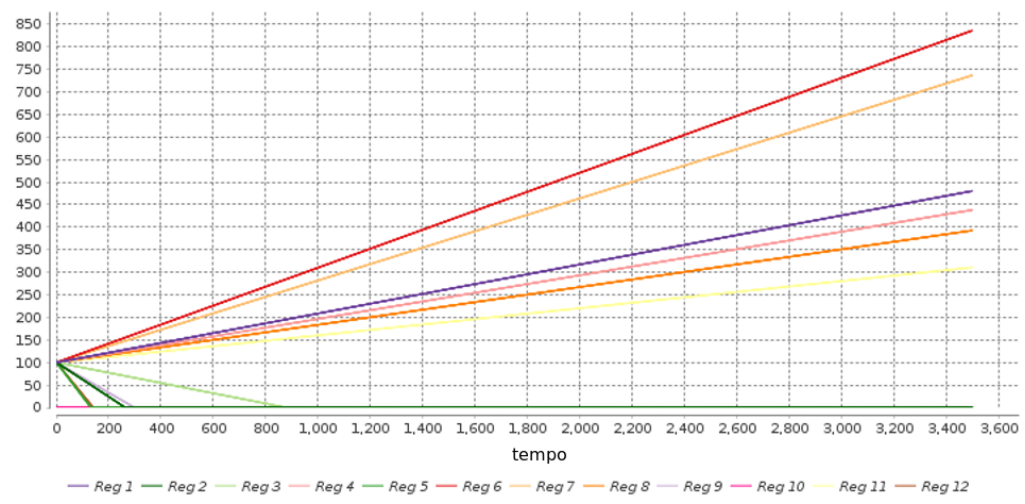

(a) volume de água por região

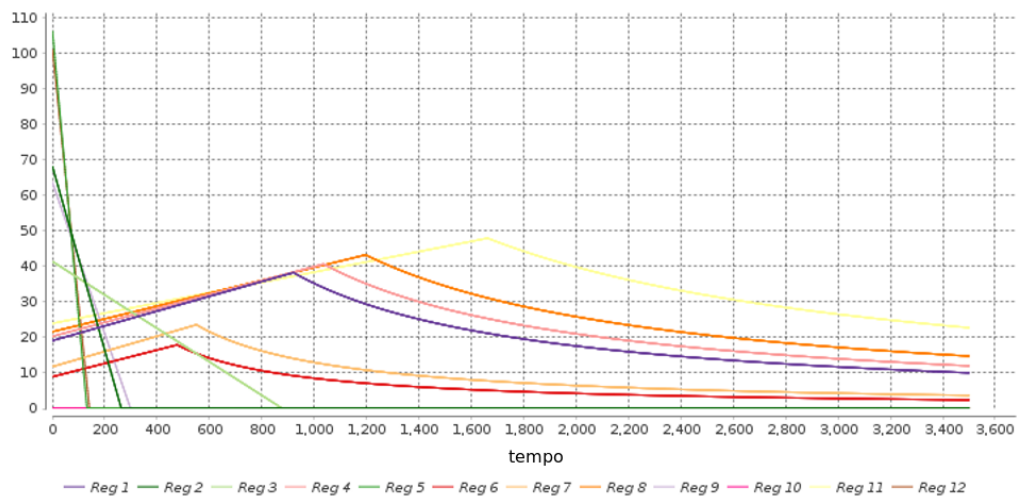

(b) produção por região

Figura 10. Variação do volume de água e produção baseada no tamanho da área da região (SEM partilha de água) 
produção até atingirem o volume máximo de água max_vol $=200$, a partir deste ponto a produtividade diminui porque a região começa a sofrer com alagamento cada vez maior no decorrer do tempo, conforme podemos observar nas Figura 10b e Figura 12b. Nesta simulação também pode-se observar que:

i. todas as regiões com cons $<0.15$ acabam sofrendo com alagamento (Figuras 9c e 11c), exceto a região 10, que acaba secando por não possuir rios; ii. a região 3, na simulação com cálculo baseado no valor da área, apesar de possuir vizinhos aptos a partilhar água, ao contrário do que ocorre na simulação com partilha de água e cálculo baseado na área, acaba secando e tornando-se improdutiva;

iii. a produtividade das regiões está diretamente relacionada com o volume de água, que não deve ser muito alto (alagamento) nem muito baixo (seca).

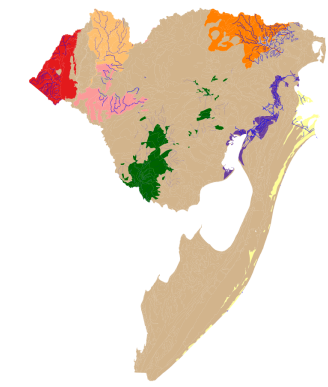

(a) 100

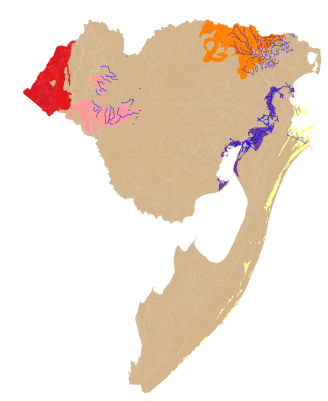

(b) 500

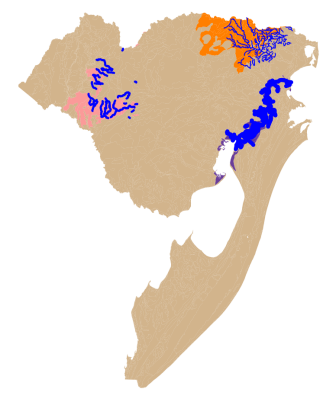

(c) 7500

Figura 11. Alterações no ambiente no decorrer do tempo baseadas no tipo de uso do solo da região (SEM partilha de água)

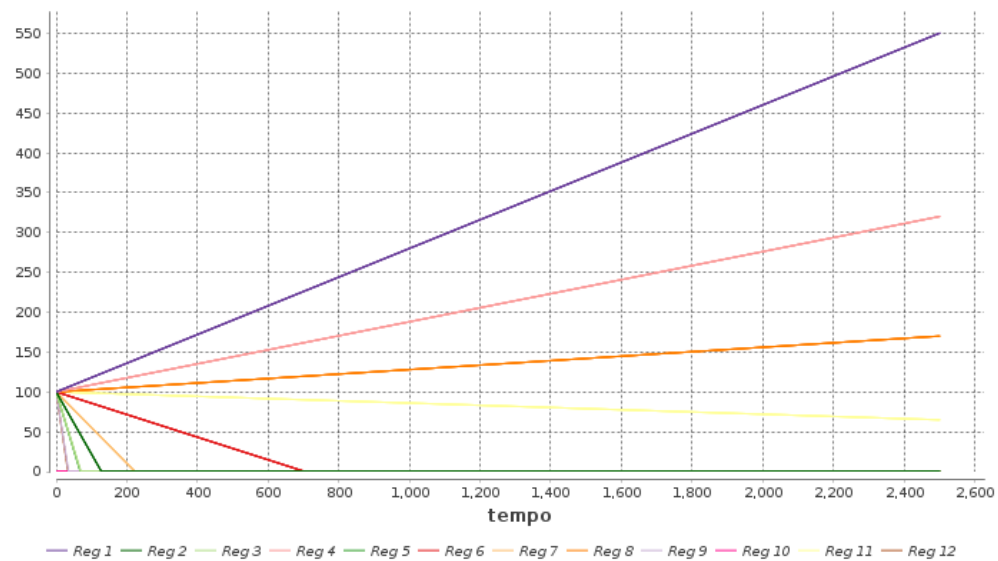

(a) volume de água por região

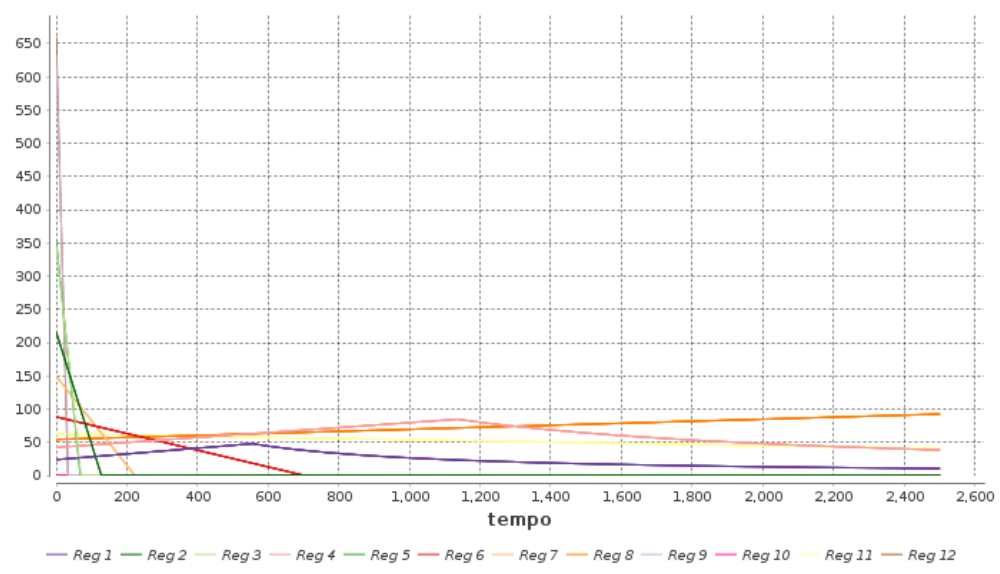

(b) produção por região

Figura 12. Variação do volume de água e produção baseada no tipo de uso do solo da região (SEM partilha de água) 


\section{Conclusões e Trabalhos Futuros}

Com o uso da ferramenta GAMA, a gestão participativa pode ser simulada sem gerar consequências efetivas. Dessa forma, para a modelagem deste trabalho, foi possível simular algumas situações entre as regiões hidrográficas determinadas. Assim, pode-se concluir que cada agente interfere de forma significativa no ambiente dos demais. Quando a tomada de decisão é realizada de forma participativa, as partes envolvidas tendem a melhorar suas condições ou pelo menos permanecer estáveis diante de possíveis problemas. Já a situação inversa apresenta situações preocupantes, pois neste caso, quando os agentes não compartilhavam seus recursos, a maioria deles obteve grande perda ou perda total da sua produção.

Neste trabalho foi apresentada uma abordagem inicial da simulação de uma bacia hidrográfica, desconsiderando o seu real comportamento com relação ao fluxo de rios entre as regiões. Para trabalhos futuros, um dos objetivos principais será acrescentar uma modelagem matemática do fluxo de água nessa bacia. Sendo assim, podem ser abordados, por exemplo, assuntos como qualidade de água, distribuição real de água entre as regiões de estudo e análise da poluição e seu impacto ambiental, como tratado em [42].

\section{Agradecimentos}

Os autores deste artigo agradecem ao Programa de apoio ao Ensino e à Pesquisa Científica e Tecnológica em Regulação e Gestão de Recursos Hídricos - Pró-Recursos Hídricos Chamada $\mathrm{N}^{\circ} 16 / 2017$, pelo auxílio financeiro no desenvolvimento desta pesquisa.

\section{Contribuição dos Autores}

Todos os autores contribuíram de forma significativa para o desenvolvimento do trabalho, nas discussões sobre a modelagem do problema, bem como na análise e desenvolvimento das simulações. A parte relacionada a introdução, especificações e trabalhos relacionados teve uma maior contribuição das autoras Míriam Born e Bruna Leitzke. A parte relacionada a implementação na plataforma GAMA, tanto no tocante à modelagem quanto no desenvolvimento das simulações, teve uma maior participação do autor Giovani Farias. Os autores Marilton Aguiar e Diana Adamatti contribuíram de forma expressiva na escrita, organização e correção do texto.

\section{References}

[1] FULLER, M. M. et al. Computational science for natural resource management. Computing in Science \& Engineering, IEEE Computer Society, v. 9, n. 4, p. 40, 2007.

[2] HOLZMAN, B. Natural Resource Management. 2009. [Online; accessed 30 apr. 2019] http://online.sfsu.edu/bholzman//courses/GEOG 20657/.
[3] FILATOVA, T. et al. Spatial agent-based models for socio-ecological systems: Challenges and prospects. Environmental modelling \& software, Elsevier, v. 45, p. 1-7, 2013.

[4] ADAMATTI, D. F. Inserção de jogadores virtuais em jogos de papéis para uso em sistemas de apoio à decisão em grupo: um experimento no domínio da gestão de recursos naturais. Tese (Doutorado) - Escola Politécnica - Universidade de São Paulo, São Paulo, Brasil, 2007. Doi:10.11606/T.3.2007.tde-07012008-154915.

[5] TAILLANDIER, P. et al. Building, composing and experimenting complex spatial models with the GAMA platform. GeoInformatica, Dec 2018. Disponível em: 〈https: //doi.org/10.1007/s10707-018-00339-6〉.

[6] PAGE, C. L. et al. Cormas: A multiagent simulation toolkit to model natural and social dynamics at multiple scales. International Conference of the Resource Modeling Association 2000 : The ecology of scales, Wageningen, p. 1-20, Jun 2000.

[7] GAUDOU, B. et al. The MAELIA multi-agent platform for integrated analysis of interactions between agricultural land-use and low-water management strategies. In: ALAM, S. J.; PARUNAK, H. V. D. (Ed.). Multi-Agent-Based Simulation XIV. Berlin, Heidelberg: Springer Berlin Heidelberg, 2014. p. 85-100.

[8] SECRETARIA do Meio Ambiente e Infraestrutura L040 - Bacia Hidrográfica da Lagoa Mirim e do Canal São Gonçalo. 2019. Https://www.sema.rs.gov.br/1040-baciahidrografica-da-lagoa-mirim-e-do-canal-sao-goncalo [Online; accessed 31 mar. 2019].

[9] BOUSQUET, F.; PAGE, C. L. Multi-agent simulations and ecosystem management: a review. Ecological modelling, Elsevier, v. 176, n. 3-4, p. 313-332, 2004.

[10] COPPIN, B. Inteligência Artificial. 3. ed. Rio de Janeiro: LTC, 2010.

[11] WOOLDRIDGE, M. An introduction to multi agent systems, department of computer science, university of liverpool, uk. John Wiley \& Sons, Ltd, 2002.

[12] BORDINI, R. H.; VIEIRA, R.; MOREIRA, A. F. Fundamentos de sistemas multiagentes. v. 2, p. 3-41, 2001.

[13] ALVARES, L. O.; SICHMAN, J. S. Introdução aos sistemas multiagentes. Brasília - UnB, p. 1-37, 1997.

[14] HÜBNER, J. F.; BORDINI, R. H.; VIEIRA, R. Introdução ao desenvolvimento de sistemas multiagentes com jason. XII Escola de Informática da SBC, v. 2, p. 51-89, 2004.

[15] SANTOS, F. P. D. et al. A multiagent-based tool for the simulation of social production and management of urban ecosystems: a case study on san jerónimo vegetable gardenseville, spain. Journal of Artificial Societies and Social Simulation, Journal of Artificial Societies and Social Simulation, v. 19, n. 3, p. 1-12, 2016.

[16] BOISSIER, O. et al. Multi-agent oriented programming with JaCaMo. Science of Computer Programming, 2011. 
[17] BORDINI, R. H.; HüBNER, J. F.; WOOLDRIDGE, M. Programming multi-agent systems in agentspeak using jason. John Wiley \& Sons, 2007.

[18] RICCI, A. et al. Environment programming in CArtAgO. Springer, p. 259-288, 2009.

[19] HüBNER, J. F.; SICHMAN, J. S.; BOISSIER, O. Developing organised multiagent systems using the MOISE+ model: programming issues at the system and agent levels. Int. J. Agent-Oriented Software Engineering, v. 1, n. 3/4, p. 370-395, 2007.

[20] LI, G. et al. Water-energy-food nexus in urban sustainable development: an agent-based model. International Journal of Crowd Science, Emerald Publishing Limited, v. 1, n. 2, p. 121-132, 2017.

[21] Le Page, C. et al. Exploring how knowledge and communication influence natural resources management with ReHab. Simulation \& Gaming, SAGE Publications Inc., v. 47, n. 2, p. 257-284, apr 2016.

[22] ADAMATTI, D. F.; SICHMAN, J. S.; COELHO, H. An analysis of the insertion of virtual players in GMABS methodology using the ViP-JogoMan prototype. Journal of Artificial Societies and Social Simulation, v. 12, n. 3, 2009.

[23] CAMPO, P. C. et al. Exploring management strategies for community-based forests using multi-agent systems: A case study in Palawan, Philippines. Journal of Environmental Management, v. 90, n. 11, p. 3607-3615, aug 2009.

[24] FAROLFI, S.; MÜLLER, J.-P.; BONTÉ, B. An iterative construction of multi-agent models to represent water supply and demand dynamics at the catchment level. Environmental Modelling \& Software, v. 25, n. 10, p. 1130-1148, oct 2010.

[25] RUANKAEW, N. et al. Companion modelling for integrated renewable resource management: a new collaborative approach to create common values for sustainable development. International Journal of Sustainable Development \& World Ecology, v. 17, n. 1, p. 15-23, feb 2010.

[26] SOUCHÈRE, V. et al. Co-constructing with stakeholders a role-playing game to initiate collective management of erosive runoff risks at the watershed scale. Environmental Modelling \& Software, v. 25, n. 11, p. 1359-1370, nov 2010.

[27] GOURMELON, F. et al. Role-playing game developed from a modelling process: A relevant participatory tool for sustainable development? A co-construction experiment in an insular biosphere reserve. Land Use Policy, v. 32, p. 96-107, may 2013.

[28] Le Page, C. et al. Companion modelling with rice farmers to characterise and parameterise an agent-based model on the land/water use and labour migration in northeast Thailand. In: Empirical Agent-Based Modelling - Challenges and Solutions. New York, NY: Springer, 2014. p. 207-221.

[29] REBAUDO, F. et al. Agent-based models and integrated pest management diffusion in small scale farmer communi- ties. In: Integrated Pest Management. Dordrecht: Springer Netherlands, 2014. p. 367-383.

[30] Le Page, C.; PERROTTON, A. KILT: A modelling approach based on participatory agent-based simulation of stylized socio-ecosystems to stimulate social learning with local stakeholders. Springer Verlag, v. 10798 LNAI, p. 156-169, 2018.

[31] TAILLANDIER, P. et al. Gama: A simulation platform that integrates geographical information data, agent-based modeling and multi-scale control. In: DESAI, N.; LIU, A.; WINIKOFF, M. (Ed.). Principles and Practice of Multi-Agent Systems. Berlin, Heidelberg: Springer Berlin Heidelberg, 2012. p. 242-258.

[32] DROGOUL, A. et al. Gama: Multi-level and complex environment for agent-based models and simulations. In: Proceedings of the 2013 Int. Conf. on Aut. Agen. and Multi-agent Sys. Richland, SC: Int. Fou. for Aut. Agen. and Mult. Sys., 2013. (AAMAS '13), p. 1361-1362.

[33] TISUE, S.; WILENSKY, U. NetLogo: A simple environment for modeling complexity. Boston, MA, v. 21, p. 16-21, 012004.

[34] NORTH, M. J.; COLLIER, N. T.; VOS, J. R. Experiences creating three implementations of the repast agent modeling toolkit. ACM Trans. Model. Comput. Simul., ACM, New York, NY, USA, v. 16, n. 1, p. 1-25, jan. 2006.

[35] LUKE, S. et al. Mason: A multiagent simulation environment. SIMULATION, v. 81, n. 7, p. 517-527, 2005.

[36] Nguyen $\mathrm{Vu}, \mathrm{Q}$. A. et al. Coherence and robustness in a disturbed mas. p. 1-4, July 2009.

[37] TAILLANDIER, P.; BUARD, E. Designing agent behaviour in agent-based simulation through participatory method. In: YANG, J.-J. et al. (Ed.). Principles of Practice in MultiAgent Systems. Berlin, Heidelberg: Springer Berlin Heidelberg, 2009. p. 571-578.

[38] CHU, T.-Q. et al. Interactive learning of independent experts' criteria for rescue simulations. J. UCS, v. 15, p. 27012725, 2009.

[39] AMOUROUX, E. et al. GAMA: An environment for implementing and running spatially explicit multi-agent simulations. In: GHOSE, A.; GOVERNATORI, G.; SADANANDA, R. (Ed.). Agent Computing and Multi-Agent Systems. Berlin, Heidelberg: Springer Berlin Heidelberg, 2009. p. 359-371.

[40] THÉROND, O. et al. Integrated modelling of socialecological systems: The MAELIA high-resolution multiagent platform to deal with water scarcity problems. San Diego, California, United States, p. pp. 1, 2014.

[41] AMOUROUX, E.; DESVAUX, S.; DROGOUL, A. Towards virtual epidemiology: An agent-based approach to the modeling of $\mathrm{h} 5 \mathrm{n} 1$ propagation and persistence in northvietnam. In: BUI, T. D.; HO, T. V.; HA, Q. T. (Ed.). Intelligent Agents and Multi-Agent Systems. Berlin, Heidelberg: Springer Berlin Heidelberg, 2008. p. 26-33. 
Water Resources Analysis: An Approach based on Agent-Based Modeling

[42] YU, S.; HE, L.; LU, H. An environmental fairness based optimisation model for the decision-support of joint control over the water quantity and quality of a river basin. Journal of Hydrology, v. 535, 022016. 